\title{
The life cycle of a customized communication device for a child with cerebral palsy: contributions toward the PD4CAT method
}

\author{
Luciana Correia Lima de Faria Borges ${ }^{1,2^{*}}$, Lucia Vilela Leite Filgueiras ${ }^{1}$, Cristiano Maciel $^{2}$ \\ and Vinicius Carvalho Pereira ${ }^{3}$
}

\begin{abstract}
Background: In this paper, we report the results of an action research conducted to design a communication device to help a non-verbal child develop language skills. Participatory design (PD) is frequently regarded as a convenient approach for designing high assistive technology (HAT) for people with serious speech impairments. However, our literature survey has shown that PD is used in an ad hoc fashion, and so a methodological framework for the inception, construction, and evaluation of HATs is still missing.

Methods: PD4CAT, a participatory design method for customized assistive technology, was used to direct this research.

Results: This method led to the engagement of an impaired child (besides other participants) as a co-designer of a customized assistive technology for his own use. The system resulting from actions performed during this research has helped the child in his rehabilitation process by means of the customized assistive computational technology developed within PD4CAT.
\end{abstract}

Conclusion: The contributions of this action research include the improvement of PD4CAT by means of guidelines to engage a non-verbal child in participatory design practices, in order to incept his assistive computational technology.

Keywords: Participatory design; Assistive technologies; Alternative and augmented communication; Accessibility

\section{Background}

PD4CAT proposes a life cycle based on participatory design for the development process of a customized solution. This cycle must engage a multidisciplinary team as co-designers interested in the development of a solution that helps the impaired target user. By employing this method, not only the multidisciplinary team participates as design stakeholders but they also enable the impaired target user to act as a co-designer as well.

PD4CAT itself is under construction in an action research. The method is improved as a result of each development cycle, in which a new customized solution is produced for each new target user, aided by a new

\footnotetext{
* Correspondence: lucianafariaborges@gmail.com

'Escola Politécnica, Universidade de São Paulo, SP, Brazil

${ }^{2}$ UFMT, IC-LAVI, Cuiabá, MT, Brazil

Full list of author information is available at the end of the article
}

multidisciplinary team. Therefore, each new case guides the method's continuous improvement.

PD4CAT had a first immersion cycle in which ethnographic observations were conducted in a rehabilitation institution firstly to experience impaired patients' universe and to idealize computational tools which provide appropriate interaction to therapist, patient, and therapy [1].

Secondly, the effort of structuring a technique for the development of customized solutions of assistive technology was addressed in this first cycle, focused on motor and verbally impaired users, based on accommodations in traditional participatory design techniques after experiments with patients, caregivers, and therapists [2].

In a second cycle, guidelines for PD4CAT were achieved by an action research with $M$ (a cerebral palsy adult), aiming the development of his customized web mobile application [3]. 
Finally, the research herein presented describes another refining cycle of PD4CAT by applying the method in the inception, prototyping, and evaluation of a customized mobile communication device for a 4-year-old child with cerebral palsy, who is verbal and motor impaired. The desired solution should help her acquire language skills, both in writing and (artificial) speaking.

Having an impaired child as the target user is an interesting challenge for the improvement of the method. A person in early childhood, even if able to speak, needs full assistance from parents in order to make decisions. By engaging the child in the participatory design (PD) activities, we intended to learn about the intertwining of group decision-making and self-determination in $\mathrm{PD}$ and its implications in the suitability of the resulting product.

In this work, PD4CAT permits the engagement of the following people in the life cycle of a customized assistive technology solution: the impaired target user who is a patient at a rehabilitation institute, her caregiver, her teacher, her therapists, computer engineers, and communication and language scientists.

To do so, we respected the ethical rules of the Resolution 466/2012, from the Brazilian Ministry of Health, which establishes regulating directives and norms for researches involving human beings. In accordance with such resolution, the patient's mother was fully informed of research procedures and manifested her consent in participating in the research by signing the information and consent form. This form explained the benefits for the impaired user and the minimal risks it might entail. The greatest benefit was the customized computational solution that would be developed. The patient's anonymity has been respected in all research stages, as well as her physical, mental, and emotional limits.

The solution we are designing by means of PD4CAT can be seen as an advance regarding augmentative and alternative communication (AAC), as it takes the natural processes of language acquisition into consideration, so as to foster linguistic and cognitive development of the target user as well as assist her communication.

The case discussion is focused on answering important questions for PD4CAT improvement: (1) how to take into account the user's present cognitive and communicative conditions in participatory activities?; (2) considering that the target user is in her early childhood and for this reason does not have a clear judgment of what she can expect from a technological device, how to design to ensure the child's independence and autonomy?; and (3) how to take into account requirements proposed by the therapists for the child's cognitive development and language acquisition? Answers to these questions are incorporated as guidelines for PD4CAT.
This paper is organized in six sections. In Section 1, we present the literature review about researches investigating augmentative and alternative communication devices and participatory design practices with disabled users; in Section 2, we present PD4CAT; in Section 3, we describe the specificities of the target user, with emphasis on alternative and augmentative technologies which can be used for language acquisition by nonverbal children; in Section 4, we discuss the PD activities performed in this case and our findings; finally, in Section 5, we present guidelines for PD4CAT, derived from this case.

\section{Literature review}

Design activity is inherent to homo faber. User-centered design (UCD) is a widely adopted approach for moving the development focus from the business requirements towards users' needs. As interaction and its qualities became more and more determinant for systems adoption, UCD techniques for end-user involvement in design process were absorbed in software engineering processes.

User-centered design approaches were mostly technologydriven in the past, focusing on laboratory testing and findings, so-called interface-related usability problems [4]. Besides, system developers were given the power to decide what a well-designed system meant, and at the same time, they monopolized user involvement [5].

Scrivener et al. [6], in the preface to the first co-design conference proceedings, argued that 'for a variety of reasons, design is being viewed, studied and developed as a collective, collaborative, even community process'. In this scenario, UCD techniques may be no longer sufficient to ensure that all important requirements were elicited from the user and transferred into the solution.

Participatory design (PD), on the other hand, is based on managing a cooperative process in which mental models must be shared and synergy must stem from the different abilities.

PD was created in the 60s, based on ideological arguments that democracy should be fostered in by using technology, so that people participated in design activities and decisions directly and effectively [2,4,7].

Therefore, PD is the only user-centered approach that includes the final user as an equal in the designers' team [8], so that he or she becomes a co-designer [9]. Therefore, the final user is not only an information provider who answers questionnaires or performs supervised software tests. Instead, he or she is actively engaged in the design process and has more influence on the solution, which enriches all stages of the conventional software development cycle [10]. In PD practices, the user can be engaged at any stage: problem identification, requirements elicitation/analysis, design, evaluation, customization, or redesign [11]. 
When compared to other non-participatory approaches, participatory design brings some benefits, especially considering the empowerment of the user in the design process:

- Bridging the gap between the designer's/developer's and the user's perspectives, thus putting an end to the separation between these participants $[8,9,12]$

- Developing a technology that often meets the final user's needs [12]

- A higher level of the user's acceptance of the conceived technology [8], as there is a stronger feeling of property or appropriation towards the solution [9]

- Better managing the user's expectations, as he or she is part of the process [9]

\section{Participatory design of alternative and augmented communication}

There have been some researches investigating AAC devices to assist people with communication impairments. However, few of them are strictly related to our study, especially regarding the three important issues for PD4CAT presented in the introduction: (1) how to take into account the user's present cognitive and communicative conditions in participatory activities?; (2) considering that the target user is in his first infancy and for this reason does not have a full discernment of what he wants from a technological device, how to design to ensure the child's independence and autonomy?; and (3) how to take into account requirements proposed by the therapists for the child's cognitive development and language acquisition?

In the following sections, we present the papers that have directly or indirectly grounded this research keeping the focus on PD related with AAC applications or speech-impaired users or impaired children.

Besides, the literature review presenting herein other researches involving people with disabilities in the design process, which guided the development of PD4CAT, can be found in our papers presented in [1-3,13].

Beyond these, we highlight the Brazilian research initiative of Melo and Baranauskas [14] which offered guidelines for PD practices with impaired people in Brazil, presenting concepts and challenges of design for inclusion.

\section{AAC by means of PD with speech-impaired users}

Prior [15] presents PD experiences involving adults with complex communication needs (CCN) and cognitive impairment in the design of a health software program, named CHAMPION. Traditional HCI methods such as focus groups, design sessions, and rapid prototyping were adapted to include the participants. Although they had difficulties to express their needs, their disabilities were not an absolute hindrance once they had cognitive functions and skills that could be employed in some PD practices.

However, despite the possibility of including the users, some researchers prefer to involve only caregivers, therapists, and teachers, representing the target user. These are some of the reasons for such choice, as Allen et al [16] present:

- Recruiting adults with $\mathrm{CCN}$ can be extremely challenging because many $\mathrm{CCN}$ adults have physical limitations that reduce their ability to participate in research (e.g., reliance on other people for transportation to and from the research center).

- Speech-impaired people are often socially isolated, which makes contacting a wide pool of participants difficult. Thus, it can be hard to include participants with aphasia throughout the design process.

- The impaired communication of people with $\mathrm{CCN}$ can make the design process much more challenging.

\section{AAC by means of PD with speech disability experts}

Allen et al. [17] employed PD with two speech language pathologists (SLP) representing aphasic users in the design and development phase of PhotoTalk, an application for a mobile device to support face-to-face communication of aphasic people by capturing and managing digital photographs. The PD team worked together to determine key system requirements. The authors stated that the participation of these SLP allowed the team to complete the design phase of this application very quickly.

Garzotto and Bordogna [18] reported the involvement of disability experts in PD practices to generate a multimedia learning ACC tool for two cerebral palsy children presenting serious cognitive impairment.

The disability experts allowed a deep understanding of children's needs, of teachers' and language therapists' goals, and of their practices and constraints by means of discussions about videos reporting examples of therapeutic sessions for language development, semi-structured interviews, and focus groups in a contextual study [18].

Besides, the team designed and implemented a set of learning experiences - multimedia and tangible materials to achieve the established learning goals. Non-disabled classmates of the disabled children were also involved in these PD practices [18].

The PD practices were unfolded along an iterative cycle of design sketching, experience prototyping, short tests with disabled children (supported by their therapists), evaluation, and partial redesign of contents and activities.

According to the authors, the design phase with these participants helped to abstract the characteristics of 
contents and tasks that are appropriate to meet the educational goals for the users' profile [18].

\section{AAC by means of PD with disabled children}

Our literature research found no results that included communication-impaired children in PD experiences. We found two studies that engaged disabled children in UCD techniques but not as actively as in PD.

In the first study by Black et al. [19], the disabled children acted in an UCD approach. In that research, a 10-year-old child and a 17-year-old teenager with severe speech and physical impairments (SSPI) were subjects of ethnographic observations for the evaluation of a mobile phone application intended to enable data collection for a personal narrative system for children.

In the second study, Garzotto and Bordogna [18] involved two cerebral palsy children (a girl and a boy, aged 10 and 11, respectively) in the evaluation of the aforementioned multimedia learning ACC tool, at the end of the design phase.

However, according to our understanding, when a user is only participating in ethnographic observations or evaluating an application, he is not involved in the PD. This is much closer to the traditional UCD. It is also important to note that real PD is far more complex, demanding an active participation of the user, who must express his needs and perspectives, desirably from the first design stages, so that he acts as a co-designer of his solution [10].

Our research aimed to surpass the challenges of this active participation by doing PD with SSPI people. The life cycle development conducted with a cerebral palsy child (named here as MI) is described in the next sections, reporting on how we have dealt with these challenges.

\section{PD by means of disabled children and aphasic people} Druin [20] and Frauenberger et al. [21] state how challenging it is to involve children in the design of technology meaningfully. And when it comes to disabled children, the challenge is even bigger.

Guha et al. [22] present an inclusionary model which enables design with children with special needs. The model suggests that appropriate involvement of children with special needs in design process begins with the level of involvement.

This model is based on Druin's levels of involvement: (1) involvement, the researchers must define how involved with the child they can get in the design process; (2) nature and severity of the disability, the child's limitations define how far he can participate, as a design partner (more engaged in the PD), as an informant, or as a tester (less engaged); (3) availability and intensity of support, the physical or human support given to the disabled child will enhance his chances to participate in the PD. Then, for example, 'a child with autism may only be able to participate as a tester given no support; however, given a one-on-one special education aide plus a communication device, the child could be a full design partner'. Likewise, 'a deaf child may not be able to participate at all unless provided with a sign language interpreter, which could open up many levels of involvement for the child' ([22], p. 63).

Besides studies involving PD and AAC, we have found in the literature review few researches on engaging people with disabilities in the PD process that can be related to the study herein presented. As follows, we present related works that involve in PD either children with disabilities in other functions rather than communication or adults with communication impairments.

Frauenberger et al. [21] present a design approach to interpret inputs from children with autism and Asperger's syndrome so as to create an interactive technology. With a view to an immersion in the context of children with autism and Asperger's syndrome, the researchers observed their school routine and asked the children to explore sensorial and functional objects and digital prototypes. Later on, these children provided insights for the design when, by interacting with sensorial objects, they produced drawings and models for objects that might interest them.

Duysburgh et al. [23] researched on the ideation process of interactive applications for hearing-impaired children. Although that research presents a design process divided into inspiration, ideation, and conceptualization phases, the children with hearing impairments were not actively involved in the PD. They were only observed in etnographic activities in the inspiration phase, during class/leisure situations, and interacting with other children. In the inspiration phase, the children's parents and teachers were interviewed. Finally, in the contextualization phase, teachers discussed on storyboards presented by the design team. Therefore, in that research, we can see little active engagement of the target-impaired users and their proxies in the PD.

Millen et al. [24] describe a participatory design approach used for the design and review of collaborative virtual environment scenarios. The authors adapted a method used for participatory design with typical children for involving children with autism.

In order to adapt the methodology, the specialist teacher with many years of experience of working with students with autism played an important role in developing a prototype feedback system to be used with autism children in the PD process.

Therefore, relying on teachers and experts to assist in the adaptation of PD techniques for autistic children, as well as supporting the interaction with the children at the time of the PD practice have proved to be successful alternatives to facilitate the inclusion of children with autism in PD. 
Galliers et al. [25] explore the issue of empowering people in design when their communication skills are impaired. That case study examines how people with aphasia participated in a design project: a workshop to develop a gesture therapy tool. Five people with aphasia, employed as consultants, took part in game playing activities followed by hands-on interaction with interactive prototypes. Although the impaired users in that research were not children, the following challenges and guidelines could be extracted for our research:

- Challenges for the inclusion of aphasic people in PD: (1) difficulties to understand and produce spoken/ written language. Most aphasic people use gestures, drawing, or facial expressions to communicate; (2) people with aphasia present attention deficits; and (3) according to their personality, aphasic people may find it difficult to deal with the frustrations of not being able to communicate or not fully understanding what is happening or being required of them.

- Guidelines to include aphasic people in PD: (1) due to the difficulty to understand and communicate, it is important that participants understand what is required of them, so that researchers should speak slowly, use repetition, speak sentences with only one clause at a time, double-check understanding, etc.; (2) to prevent distraction, design sessions must last as short as possible, extraneous conversation must be avoided in the same room, and there should not be an overflow of information on the computer screen; (3) mutual learning between designers and end users is important; (4) aphasic people must feel they were listened to and their opinions were taken into account; and (5) workshops over an extended period of time enable valuable relationships between participants.

\section{PD4CAT}

In this section, we present a macroscopic view of PD4CAT. As previously mentioned, PD4CAT is being continuously improved by action research from results of new development cycle. Experimenting PD4CAT in particular situations adds details to each phase.

According to Bratteteig et al., PD is based on users having a say which 'means having something to say as well as affecting the outcome of an activity with what you say - i.e. having an influence. To enable users to have an influence implies that the users need to be informed, they need to be given the chance to form and express their opinion, and they need to be given the power to influence the decisions in design'. ([26], p. 117).

Still according to Bratteteig et al.,'Methods are generalisations from a vast amount of empirically based experiences on how to conduct Participatory Design. A Participatory Design method cannot be applied like a cookbook recipe, but provides general guidelines that must be carefully selected, adapted and appropriated to the specific project and situation at hand'. ([26], p. 117).

PD4CAT is a PD method in which the focus is allowing non-verbal users to have a say in their own assistive technology. PD4CAT fundamental objective is to allow the target user with a disability to act as co-designer in the development of a customized, high assistive technological solution that meets desired requirements, with the help of people concerned with the user's well being.

'People concerned with the user's well being' are often his or her therapists and caregivers. Their knowledge about the user's needs and their ability of communicating with the user help on including the disabled user as an active participant in the design process. Usually, the development team does not possess this knowledge. In this paper, the multidisciplinary design team that includes the user with a disability is referred to as the devteam.

PD4CAT is, as an interactive systems development method, anchored in a cyclical life cycle in which a prototype is successively refined based on analytical and empiric evaluation of its qualities, as many UCD methods like Mayhew's [27], Hix and Hartson's Star [28], and many others. Also, because a working product is desired as an outcome, PD4CAT has also an underlying software engineering activity, based on reusable components, that is not described in this paper but is responsible for the implementation of the designed solutions.

PD4CAT was structured into five phases based on the conventional structure of a software development cycle, especially Sommerville's [29] incremental model and on a simple model of design process (cycles of needs and requirements analysis, (re)design, construction of interactive version, assessment, final product) [9,30]. Besides, this method uniquely explores techniques that use a PD approach throughout the process, so as to a include the disabled user.

Each phase of PD4CAT presents specific requirements that lead to the method's main goal. Those phases were proposed after a preliminary ethnographic study [3], where our team of computing science researchers observed the context of a rehabilitation institution for 6 months. We observed many therapeutic sessions involving therapists, patients, and caregivers. We also made formal and informal interviews with these subjects, so as to understand the therapeutic process and possible technological needs. As a result from those observations, we realized the need for customized solutions and the importance of PD in conceiving these technologies.

Based on these results, we modified the conventional interactive software development life cycle so as to engage 
final users as co-designers and proposed the first version of PD4CAT. This first version was used to develop an AAC solution for a user with disabilities, with a first devteam. By doing so, improvements were introduced in the second version of PD4CAT method [3].

This paper presents the second experiment with a second impaired user and the resultant improvements to PD4CAT.

PD4CAT five phases are: (1) team composition, (2) solution inception, (3) solution detailed specification, (4) solution design, and (5) evaluation. A backing activity, which is named Support for PD, does not affect the solution product directly but supports the other phases in the process by means of adjusting strategies and necessary artifacts to PD activities.

Figure 1 presents the flowchart of the method phases. As it can be seen in the figure, some of these phases are typical of a conventional interactive software development process: analysis, design, construction, and evaluation and should be done cyclically as expected for interactive systems. What make PD4CAT unique are the first phase, team composition, the process support activity, and other characteristics of PD that take into account the participation of all stakeholders in the development phases. In order to make this uniqueness visible, we include in the phase description in the following sections a list of requirements which must be assured.

PD4CAT main phases are performed according to the regular order of the flowchart which is $1,2,3$, and 4 . However, in the flowchart, these phases are connected in twoway relationships because interactive software is usually produced iteratively; it is frequently necessary to refine the results of a previous stage before moving on to the next one.

Phase 1, team composition, consists of the initial contacts among the members of the dev-team, which, in this research, is composed of computer engineers, health professionals, impaired target users (the rehabilitation patients), and their caregivers.

As a result of this phase, people selected for the devteam are introduced to the PD practices and to PD4CAT, so as to customize an assistive technology for the needs of the impaired target user.

The requirements for this phase are as follows:

- Engaging the specialists from the rehabilitation institute who will act as co-designers of the technological solution for the user. They will also help including the impaired user as a co-designer in the PD process with PD4CAT. Specialists from the rehabilitation institution are usually named by their

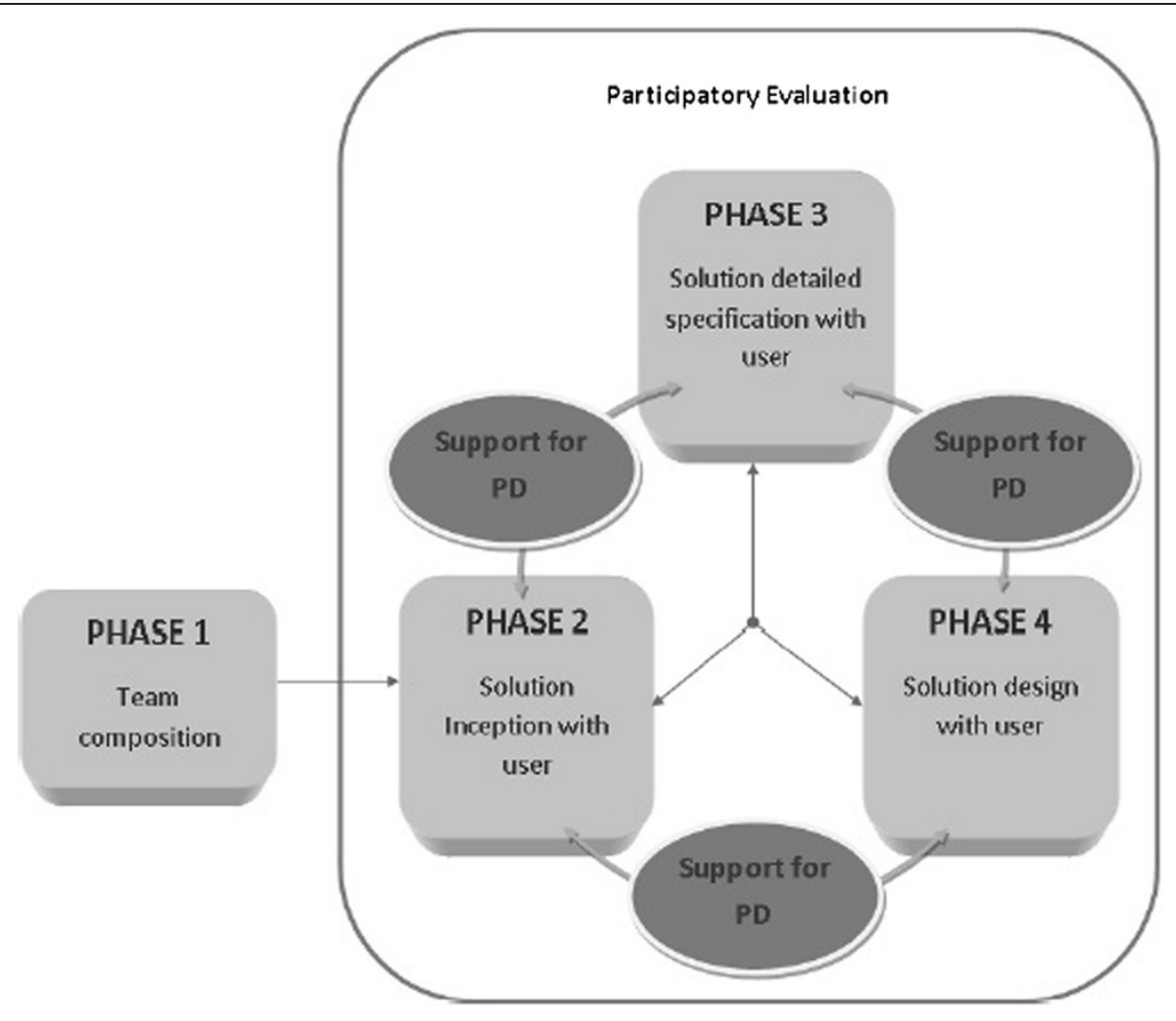

Figure 1 PD4CAT phases. 
superiors or by colleagues who have already entered the dev-team.

- The specialists group indicates a list of patients who could be engaged in PD with PD4CAT. Priorities are defined based on criteria established by those specialists.

- Selecting the user from the patients list, presenting him with the proposal and evaluating his desire (and if it is feasible) to engage in the PD process. The specialists from the rehabilitation institution must help in the communication and interaction with the user.

- Addressing ethical concerns to warrant benefits to the user and minimize risks.

PD support phase develops along with the phases called developing solution, solution detailed specification, solution design, and participatory evaluation of the prod$u c t$. This phase PD support provides the necessary tools to support the implementation of participatory design practices in each phase of the process, also ensuring the necessary involvement of the dev-team.

These tools comprise selected technologies and materials that meet the needs of the experiment, focusing on the process of participatory design. They also involve the development of techniques to engage participants of the dev-team, especially the impaired person.

The process of either creating or adapting such techniques can be summed up in the following script for participatory design practices: step 1, activities of participatory design with specialists and people close to the impaired user, so as to produce the results expected for each PD4CAT phase; step 2, activities of participatory design to develop techniques that may engage the impaired user in step 1; and step 3, employing the technique developed by the specialists in participatory design activities now including the impaired person as the principal stakeholder.

Phase 2, solution inception with user, is the phase in which the user's context is investigated and his therapeutic and daily needs are detected, in order to identify specific computational solutions for him.

To do so, interviews are firstly conducted with the user's therapists. Then, the user is watched in therapeutic sessions. Therapists and caregivers must help in this phase by interacting with the user to help answering the previously arisen questions. Those questions are intended to guide the dialogue between therapists and user, so as to unveil his needs and expectations on possible technological solutions that might improve his autonomy and independence. Besides, if necessary, specialists must support the understanding of the user's communication. The results are analyzed by the therapists and the user, so as to indicate a high level solution to benefit the user.
Therefore, the requirements for this phase are as follows:

- Understanding the user's context, needs, and expectations with the aid from the therapists and from the own patient

- Defining quality attributes for the solution, with the aid from the dev-team

- Proposing a technological solution to help the patient

Phase 3, solution detailed specification with user, aims to detail functionalities for the solution indicated in phase 2.

Detailed functionalities for the solution are designed with therapists by means of exploring techniques such as focus group discussions, brainstorming, and prototyping. Then, therapists and computer science researchers create strategies to specify solution functionalities by adapting techniques together with patients. The designed strategy is applied to the user who specifies details for the solution. Necessary adjustments are made so that the strategy meets its purpose.

Therefore, the requirements for this phase are as follows:

- Getting ideas from therapists about relevant details for the solution. Those ideas must be elicited from the high-level solution generated in phase 2.

- Defining strategies with therapists to propose PD practices that allow the impaired user to participate in the solution specification.

- Obtaining the solution specification together with the impaired user by using the inclusive technique defined with the therapists.

- Relying on the aid from therapists and caregivers to include the impaired user in PD.

- Checking with the dev-team if the usability attributes previously conceived were met by the solution in PD practices.

In phase 4, solution design with user, the interaction design project is defined to conceive a good usability interface.

Initially, participatory practices are carried out with the therapists to make a first draft of the interfaces. It is suggested to do prototyping together with focus group discussions, brainstorming, interviews, or observations of the patient. Later on, strategies are planned with the dev-team to permit including the user in interface design practices.

Those strategies are applied to the caregiver and the patient, who must provide his own interface design. At this moment, strategy adjustments must be made again so that they work properly. 
Therefore, the requirements for this phase are as follows:

- Drafting (or designing) interfaces with therapists

- Defining strategies with therapists to include the impaired user in the interface design

- Drafting (or designing) interfaces with the impaired user by performing the strategies defined with the therapists

- Checking by means of PD practices with the dev-team, if relevant quality attributes for the solution are met

Besides these phases, participatory evaluation of the product happens in the beginning of each new meeting with the dev-team by means of informal discussions, in order to evaluate the results of previous team actions. This phase must be repeatedly performed from phase 2 to phase 4 .

The requirements for this phase are as follows:

- Checking if the design met the dev-team's expectations.

- Proposing PD activities that allow the dev-team to suggest improvements to the solution.

- Engaging the impaired user in the evaluation process.

- After handing in the solution to the final user, defining strategies for gathering feedback from him and from his caregivers on the daily use of the technology developed. Those strategies may include field diaries, software monitoring, periodical meetings, observation of use, focus groups with therapists, etc.

According to each phase of PD4CAT, the results to be evaluated must match the requirements of the solution and the low $^{\mathrm{a}}$ and high-fidelity prototypes ${ }^{\mathrm{b}}$, which will lead to the final product.

\section{PD4CAT for a non-verbal child}

A design case involving a non-verbal child and the use of PD4CAT is presented in the next sections.

\section{Phase 1 - dev-team composition}

This case study was developed by a group of specialists comprising four communication therapists from a rehabilitation institute (an educational psychologist, a psychologist, a speech therapist, and an occupational therapist), six computer science researchers (including field researchers and developers), a language scientist, and a visual designer specialist besides the impaired target user and her caregiver.
From now on, we will name as 'specialist members of the dev-team' the rehabilitation specialists, the computer specialists, the language scientist, and the design specialist, in summary, all the dev-team except the user and his or her caregivers.

According to PD4CAT, only one impaired patient is selected to act as a co-designer of his own customized solution. In this research, the rehabilitation specialists were in charge of making this choice, as they know the needs and history of each patient. Therefore, they could use this information to select which patient, with his special needs, would best profit from a computational solution. The therapists consensually chose a 4-year-old girl, named MI, to participate in this research. Her profile will be further described in the next section.

It was not difficult to make the multidisciplinary team familiar with the PD4CAT method, once the specialists on rehabilitation, computer science, and communication had already worked with PD4CAT in the first action research, when developing a customized solution for another impaired user. It was only necessary to integrate the language specialist, the new impaired target user, and her caregivers to the group.

All the new members were introduced to the work proposal by one of the computer science specialists. They were introduced to the goals, the major practices, and some practical examples of PD activities previously conducted with another impaired target user.

Such explanation had to be adapted to MI's cognitive capacities and experience; therefore, it was presented to her by a closer person: the psychologist of the dev-team. This was done to prevent any incidental distress to MI by a stranger's approach.

\section{Phase 2 - solution inception}

In order to envisage an interesting solution for a patient, it is necessary to understand his lifestyle and particular needs. In our research, we decide on the assistive technology that may have the biggest impact on improving the patient's well-being. For MI, the therapists and caregivers who usually interact with her were asked to present the child's characteristics and needs in relation to assistive solutions that might benefit her daily routines or her therapy. Besides that, researchers and computer engineers also attended and observed some of her therapeutic sessions, as we report in the next sections.

Getting to know MI According to MI's caregiver and therapists, she is a child with cerebral palsy, verbal and motor impaired, but she clearly understands what is said to her.

Regarding her motor abilities, she is able to creep in a sitting position, stay on her knees, descend low staircase steps, stand up with support, and hold objects, usually 
with the left hand, which is more efficient. She uses an adapted wheelchair, either moving it on her own or being pulled by someone else.

As for the verbal impairment, the patient makes an effort to communicate, but her speech is unintelligible. According to a therapeutic evaluation, MI is not expected to develop her speech, in spite of the rehabilitation procedures. At home, she communicates to her family with gestures she herself creates. According to her mother, MI uses home signs meaning: drinking, eating, bathing, perfuming, playing videogames, using the cell phone, dancing, standing up, playing with dolls, pain, and physiological needs.

MI goes to nursery school every day, full time, and like most 4-year-old children, she is not expected to be able to read or write.

MI has a paper communication board, made by her therapists, which she uses properly according to them. However, she prefers to communicate with gestures, sometimes rejecting the board, according to her school teacher. The therapists strongly believe that this rejection to the board must be overcome because the patient needs to learn how to communicate with people who do not know her gestures. Besides, she must be stimulated to use expressions in her mother tongue. These stimuli are intended to help her learn to read and write, so as to develop her autonomy.

Watching MI MI was watched by specialist members of the dev-team during her therapeutic sessions in the rehabilitation institute. During the observation, the team learned about her personality and preferences. Her mother said MI likes playing with pictures, taking photos, and filming with a cell phone, as well as playing some games on it. After these comments, MI was given a cell phone and was asked to show how to photograph with it. MI did it skillfully (Figure 2) and, after taking some photos, started playing a game in the cell phone (Figure 3). The patient showed easiness and pleasure when doing these activities.

The therapists carried out some other activities with MI, who succeeded in recognizing colors and matching pictures.

During the session, the patient also demonstrated how she uses her paper communication board by accurately pointing the images on the board.

Her mother also stated how difficult it is to add new images to the paper board, as she does not have easy access to computers. Nevertheless, she needs to add images of more specific toys, such as MI's doll and her plastic pans, as well as new family photos. She also suggested that some of these images could be photographed and others could be taken from the internet. Besides that, she said some images are not being used in the board, so that they could be removed.

Analyzing solutions for the case In this phase, computational solutions for MI are discussed with the specialist members of the dev-team and caregivers.

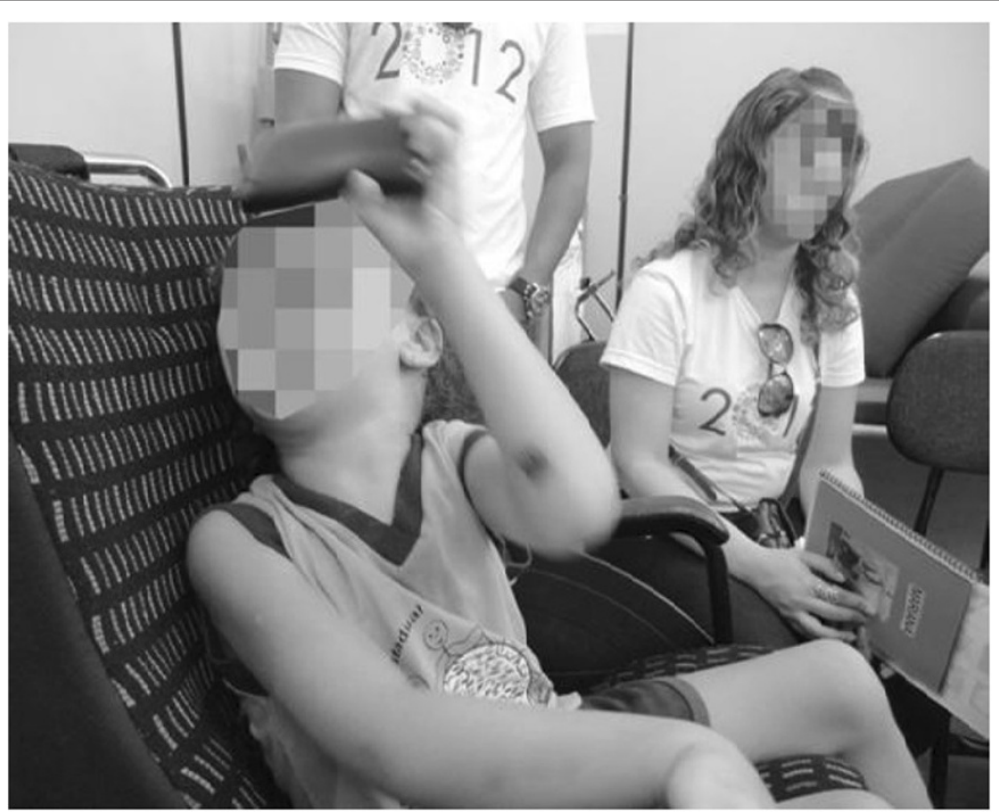

Figure $2 \mathrm{Ml}$ taking photos with the cell phone. 


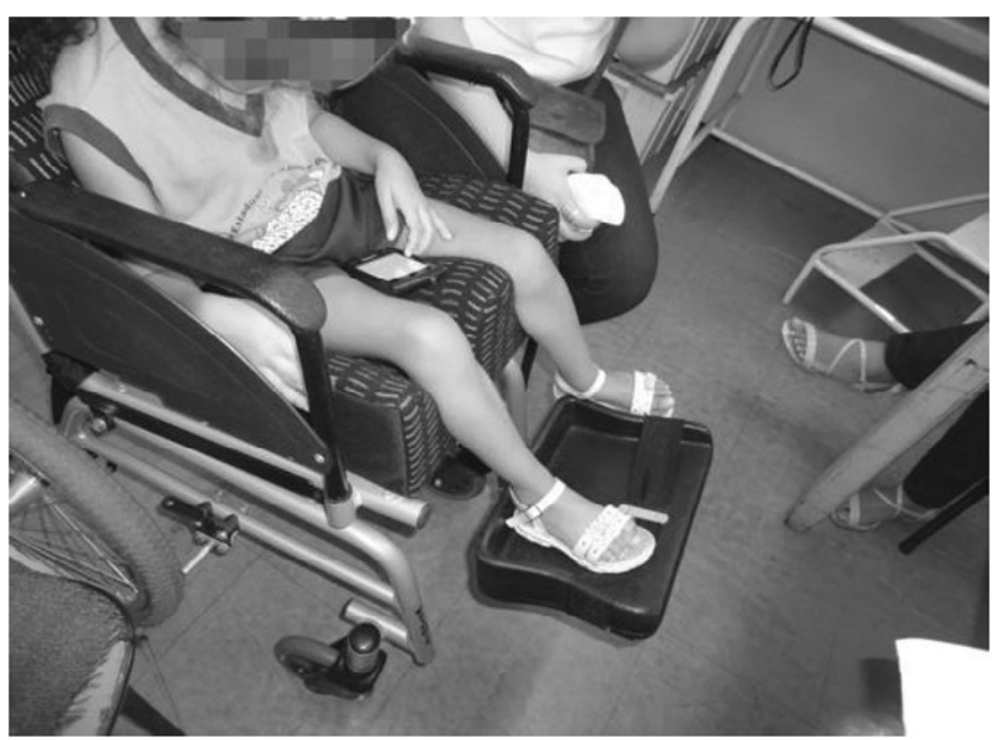

Figure $3 \mathrm{Ml}$ playing a game in the cell phone.

We must emphasize that in PD4CAT, some professionals usually compose the multidisciplinary team: the therapists, caregivers, and computer specialists. However, in this case, because therapists manifested concern with language acquisition, a language scientist was invited to participate of the dev-team.

MI's therapists stated that it is fundamental to enable the patient to communicate with others. After discussing this issue, the group proposed a mobile computational device (a tablet), in which the patient would be able to handle pictures that emitted previously recorded sounds. Those should be combined to form sentences, thus helping MI's communication. Several ideas were suggested, such as it should be an electronic communication board, adapted to MI's needs,' 'there should be a touch screen virtual keyboard,' 'pictures should be drawn according to a standardized pattern, 'the name of each picture should be shown under the drawing', and 'pictures should represent her daily routine'.

Later on, a similar idea was proposed by MI's mother, who suggested an electronic board, similar to a touch screen cell phone, in which images could be updated. She also added that it would be necessary to couple the board to MI's wheelchair, so that it would be easier and safer to use the device. The idea of an electronic board that could be personalized was recommended by all participants of the dev-team.

The therapists pointed out that a communicator unable to produce syntactically structured sentences, merely emitting disconnected words, would hinder MI's language acquisition. As an example, the communicator should not emit the sound of verbs only in the infinitive form. Instead of that, these parts of speech should be inflected, so as to agree with the subject, according to Portuguese grammar rules.

The language scientist stated that the communicator, besides helping immediate communication with others, is expected to help MI acquire syntactic and semantic patterns. Therefore, instead of emitting sounds of individual words, the device should pronounce the final product of the sentence, after establishing the due syntactic connections.

According to the therapists, this proposal would stimulate MI towards developing her communication skills, cognition, motor coordination, and literacy. Therefore, the group decided on a communicator that must voice structured sentences with words/images combined by the patient. The sentences built with the tablet should respect grammar rules and indirectly teach these patterns to MI.

In this phase, the dev-team pointed out some usability requirements to MI's solution [31]. Usability attributes consider MI's skills, limits, needs, desires, routine, and expectations of rehabilitation, and they are expressed as follows: (1) accessibility, autonomy in routine activities and communication; (2) effectiveness, rehabilitation and oral language acquisition; (3) ease of use, considering MI's profile; and (4) pleasure, so that using the solution is pleasant to MI.

In the PD4CAT phases presented as follows, PD activities focus on attaining those usability attributes, so that the solution has the characteristics defined by the stakeholders. The solution is described in the next section.

\section{Phase 3 - solution detailed specification}

This phase comprises the detailing of the solution for MI, based on the results from the previous phase. As the 
incepted solution is intended to help MI in the rehabilitation process, it was decided that the specification of the solution should be done by the multidisciplinary team, including therapists and the language scientist.

Contributions from the language scientist Due to the multidisciplinary approach of the method, the language scientist, in a meeting with the other participants of the dev-team, cites theories on language acquisition to guide their decisions on the requirements of the solution that best suits MI's development. Such theoretical bases are now described.

According to Slobin [32], the most up-to-date theories on language acquisition consider that both experience and an innate grammar are accessed when a child learns to speak. Thus, language acquisition is not only related to repeating stimuli but also to abstracting syntactic and lexical patterns from an inner grammar, applying them to new sentences, from the input received from parents.

Therefore, the communicator must, in an early stage, allow MI to employ the most basic syntactic patterns, like verbs with only one or two arguments, in simple sentences, which are the most frequent structures in the beginning of language acquisition [33]. Besides that, considering that lexical acquisition is parallel to syntax acquisition [34], the communicator will permit MI to develop her vocabulary implicitly by classifying words as verbs and nouns, which is essential to structure clauses.

Moreover, as language acquisition is a gradual process, the application must be designed so as to allow adding new words to it, as well as new clause patterns, as MI develops her communication skills.

Therapists' evaluation on MI The therapists evaluated MI on her cognitive level, so as to guide the application development. In this diagnosis, the following methods and techniques were employed: interview with her mother; Columbia Mental Maturity Scale (CMMS), to evaluate MI's mental maturity [35]; Human Figure Drawing (HFD III) [36], to evaluate her cognitive development; and visits to the school and informal observations. Some PD sessions with MI took place in her school, where the researchers were allowed to carry out some of the research activities. Meetings at school were also convenient for the target user and the other participants of the devteam, due to logistic reasons.

From the cognitive evaluations, the therapists attest that MI has now average-superior intelligence and is able to understand verbal language despite having difficulties in fine motor coordination. Based on the evaluation of her school activities, the therapists concluded that MI's development meets what is expected for her age, considering her motor and verbal impairment.
Talking to MI This section describes the strategies employed by the dev-team to understand MI's communication patterns. In the absence of MI, one of the therapists asked the patient's mother about the girl's last weekend. The mother answered that MI had been to two birthday parties.

Later on, the therapist asked MI about her last weekend, and she answered that she had been to a relative's birthday and ate chocolate cake. To express that, she used gestures and the paper communication board. The other participants of the dev-team watched the process and occasionally posed more questions to MI.

Besides that, MI's mother and sister were asked to talk to MI, so that she was given the opportunity to use her daily gestures. The patient was happy to do so, also showing she perfectly understood what she was asked about. After each question, such as 'MI, how do you ask people to comb your hair?', the girl rapidly showed the specific gestures, which matched the ones her mother had previously told the specialist members of the devteam.

Specialist members describing MI's solution By the end of the aforesaid steps, the specialist members of the dev-team discussed on the data collected. Paperprototyping activities, based on focus group and brainstorming, came up naturally in this meeting, wherein the following requirements for MI's solution were elicited:

- The interface must present an area with pictures/ words divided into three different syntactic/lexical categories: subject, verb, and complement.

- These pictures/words must be selected and organized by the dev-team, according to MI's expression needs.

- Each category comprises a database with lexical items (words): subject and complement can be pronouns or nouns that depict MI's reality and routine; verbs, in a first stage of the communicator, must admit only one or two complements.

- Another area, below the previous one, must provide space for each selected picture/word, to be dragged and dropped by MI, respecting the syntactic order.

- In the first stage of the application, simple present will be the only possible tense for sentence structures. Other verb tenses and linguistic phenomena (noun inflections, noun and verb modifications, clauses coordination and subordination, etc.) will be added gradually in successive stages, respecting MI's development.

- Only after building the sentence in the communicator MI will click on the 'sound' button, so that the sentence is voiced. 
- The application must permit that new words are added to the database by means of new images upload and sound records.

\section{Phase 4 of PD4CAT - solution design}

This phase aims to shape the solution by prototyping highly usable interfaces for MI. Thus, the inputs from the PD with MI are essential to design the interface. The following steps describe this process.

Strategies for PD with MI The specialist members of the dev-team worked in prototyping sessions, focus groups, and paper-prototyping activities to conceive strategies to include the user in the PD, concerning aspects such as shapes, colors, interaction, and organization of the interface.

Such strategies relied on the therapists' experience in rehabilitation activities, which involve adjustments in the environment and in clinical practices according to each patient. Therefore, those strategies were spurred in PD practices so as to engage $\mathrm{MI}$ as a co-designer.

Regarding MI's preferences on images, shapes, colors, and styles (concerning the representation of the girl's reality), the following PD sequence was planned: (1) drawing with MI pictures of subjects and complements the designer would interact with the patient by drawing different images of a same object/person in either more iconographic or more realistic styles; (2) asking MI to color the most beautiful drawings, in her opinion, so as to identify her preferences; (3) drawing activities that represent verbs with $\mathrm{MI}$ - the designer would draw different representations for some verbs related to her routine; and (4) again, asking MI to color the most beautiful drawings, in her opinion, so as to identify her preferences.

A second practice was conceived to include the patient in the PD, so as to investigate the best suited interactional patterns and information organization standards for her communication. This practice involved the following steps: (1) telling MI a fairy tale (Little Red Hood); (2) showing her some cards (made by the designer) that represented people, actions, and objects from the story and from MI's routine; (3) stimulating her to form sentences by pointing to the illustrated cards, as if she were retelling the story; and (4) after MI built a sentence by pointing to the cards, one of the participants of the dev-team enunciated the clause, simulating the function of the communicator.

During this practice, the dev-team observed MI's expressions and reactions, especially concerning the way she handled the pictures, her capacity of building logical sentences and her global understanding of the activity.

Practices with MI: drawings In the rehabilitation institute where MI is regularly attended, the designer asked her to draw on white paper, using pencils and crayons. MI expressed herself either with gestures her mother and therapists translated or with her paper communication board.

The designer asked MI who she would like him to draw, and she pointed to her sister, who was in the room. The designer drew her sister in detail, and the patient felt like coloring the image. To do so, she chose very similar colors to those her sister was wearing. The dev-team asked MI who had been drawn, and she pointed to her sister. When asked if the drawing was beautiful, MI said no with a head shake. When asked if

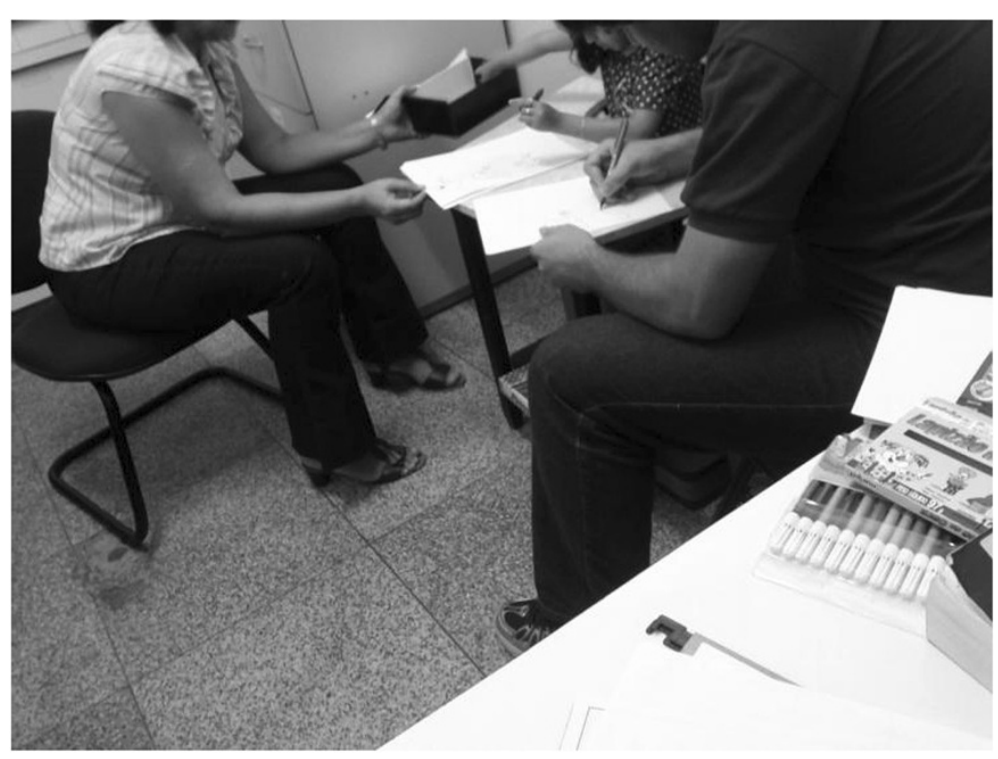

Figure $4 \mathrm{MI}$, his therapist, and the designer in a drawing practice. 
it was similar to her sister, MI answered negatively again. Figure 4 expresses a moment of this practice.

From that, one can infer that MI is able to associate drawings and real objects/people, even if their representation is not realistic.

After that, the designer drew some actions, such as eating. To express that, two images were created: (1) a person holding a spoon, in detail (similar to the representation in her paper communication board) and (2) the same person with the right hand pointing to the mouth (similar to MI's traditional gesture meaning 'eating'). The patient was asked to choose and color her favorite drawings, which she did fast. MI preferred the first drawing. The procedure was repeated for other actions, leading her to choose between images similar to those in her paper communication board or images similar to her conventional gestures. The images similar to the board were preferred in all cases. Figure 5 shows MI engaged in this practice.

Next, the designer drew both a less-detailed image and a more realistic and detailed one of many actions. When asked about her preferences, MI pointed in all cases to the most iconographic and abstract representations.

Objects were also drawn to represent actions, such as a spoon (for eating) and a glass (for drinking). However, the patient did not recognize those as actions, only as concrete objects.

The practice led to the conclusion that MI prefers simpler and more iconic images, with the same colors as the real objects she interacts with in her day-by-day.

As for the actions (verbs), the decisive point for MI associating them with the drawings was not the agent (subject) in the image but the interaction between the agent and the object (complement) he or she held.

Besides that, we observed that the patient is able to associate and memorize images, easily relating them to her dayto-day activities, even if they are not similar to her reality.

Practices with MI: story and cards This practice was performed in a room at MI's school. The patient sat on the same table she uses everyday at school.

Firstly, MI was brought by her teacher on her arms, so as to make the child feel more comfortable and safer. As the girl was a little insecure, the teacher agreed with MI and the other participants of the dev-team that she would stay there, until MI felt at ease. In order to make MI comfortable and at ease, the therapist soothed MI by approaching her table and talking to her. She explained to MI that they would play some games and that the girl would give some suggestions for a new toy in a tablet. MI smiled, expressing she liked the idea. The computer researcher showed MI the Little Red Hood book and asked the patient if she liked it. The girl smiled and shook her head affirmatively. MI tried to open the book herself and looked at the research team member as if asking to be told the story.

The stakeholder questioned whether the patient would like to listen to the story, and MI answered affirmatively. The story was told with the aid of the book illustrations. Throughout this process, questions were posed to MI, so as to make the storytelling interactive. The patient answered those questions either by pointing to the book or by shaking her head and making facial expressions. The other research team members watched this activity,

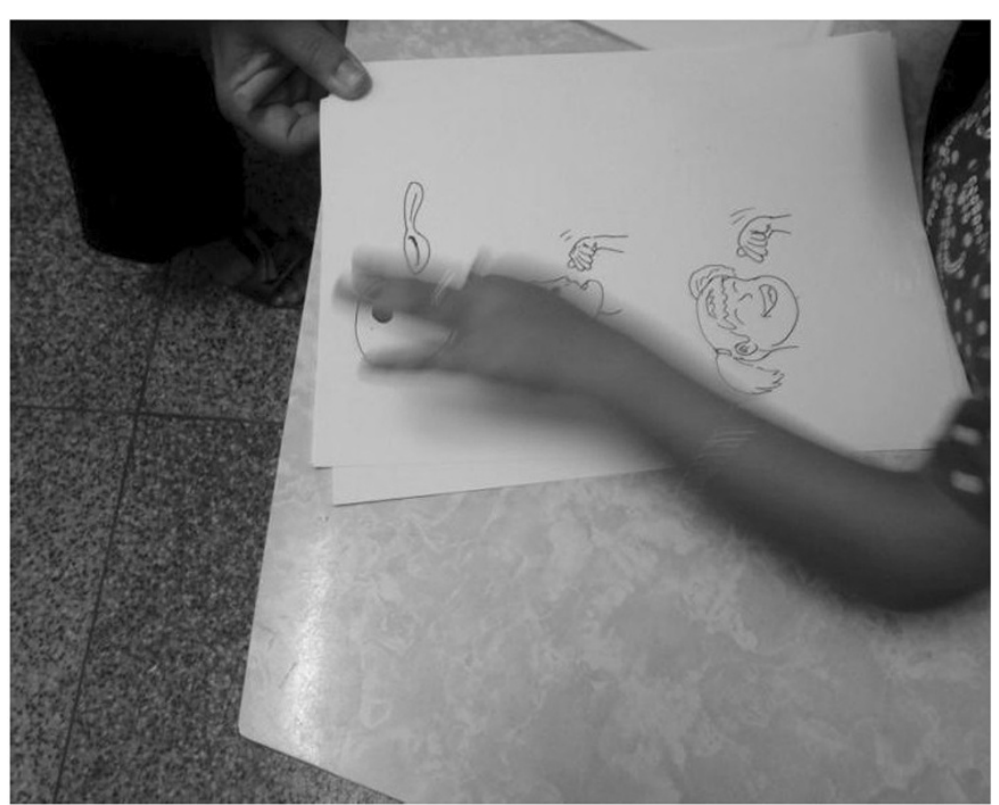

Figure $5 \mathrm{Ml}$ choosing drawings. 
sometimes helping to interpret MI's gestures, or interacting with the patient by posing more questions. MI felt more relaxed after this activity.

After the story, MI was asked to retell the story by using cards made by the designer. These cards represented some of the story characters and their objects, as well as actions and objects from MI routine. The child was very interested, smiling, and curious to play with the cards.

Sentences related to the story were proposed by the group, while the designer made some extra drawings related to the fairy tale and MI's kins, according to the drawing patterns $\mathrm{MI}$ had preferred in previous PD sessions.

From the images on the cards, the research team member asked questions like 'where is the wolf?', so that MI could point to the correct drawing with her left hand; 'The wolf is happy, does he want to sing?', and MI shook her head affirmatively; 'Which card means singing?', but MI did not find the correct card because there was just a microphone drawn on it. Then, the designer drew an iconic head with a microphone, and this card was put on the table, together with the others. When the question about singing was repeated, MI pointed to the new card.

When asked 'what does MI want to do now?', she pointed to the card that meant eating; 'Is MI hungry?', and she shook her head affirmatively. Other questions like 'Which card means drinking?', 'Where is grandmother?', 'Where is the apple?', 'Which card means sleeping?' were asked to MI, and she rapidly answered all of them. Notice that, as children first envisage themselves as a third person (he or she, instead of I), the team addressed MI by using her name as the subject of the questions, instead of the pronoun 'you'.

In order to verify her capacity of ordering words to make sentences, simple clauses were presented to her, like 'The Wolf eats Little Red Hood', and then the girl was asked 'Where is the Little Red Hood?', 'Where is the card for eating?' and 'Where is the wolf?'. MI pointed correctly to each card. Other sentences were suggested, and the individual words were correctly pointed to by MI. Finally, when MI was asked what she wanted to tell the group, the girl pointed to some cards in sequence, to indicate the sentence 'Little Red Hood goes to the grandmother's house'. Figure 6 illustrates MI engaged in this practice.

The research team presented then cards expressing 'yes' and 'no' (with thumbs up and thumbs down). MI has given preference to express short answers with head nods, instead of these cards, although she seemed to understand negative sentences using the corresponding card in a sentence, pointed by the interlocutor.

When it was time to finish the activity, MI expressed discontent with the activity interruption and manifested by gestures her longing to continue the storytelling game with the cards.

After this 90 -min session, MI was invited to play a game on a touch screen cell phone, so that her capacity of clicking and dragging in this kind of device could be evaluated. She demonstrated high skill regarding these tasks.

The described practice supports the assumption that the patient can build simple sentences composed of

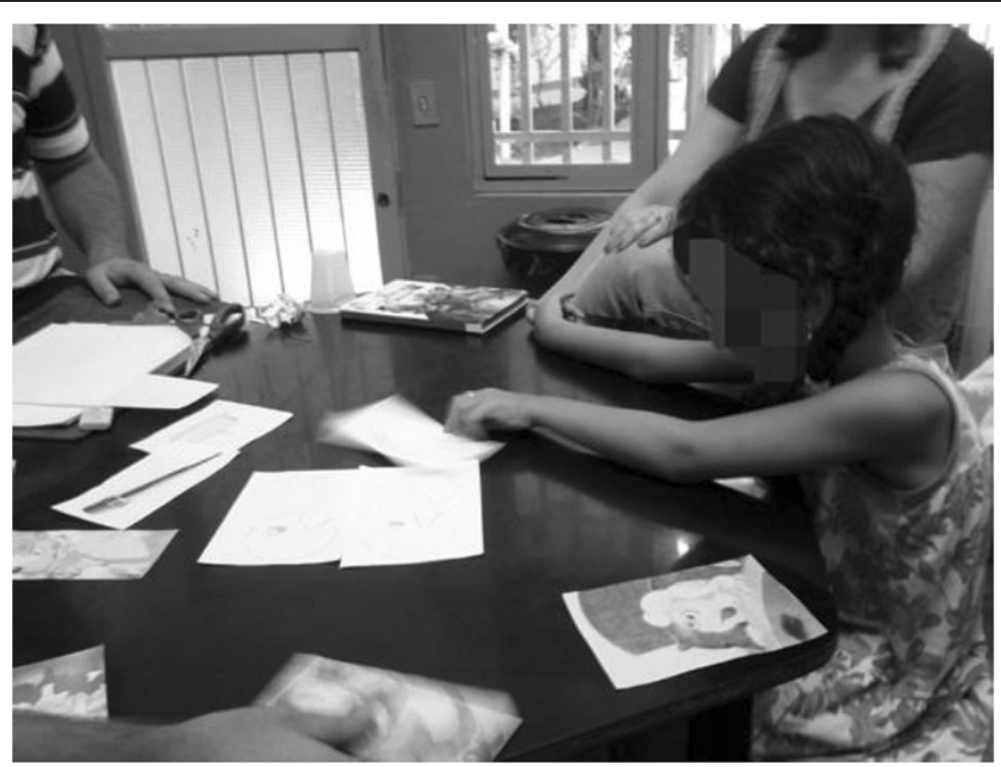

Figure $6 \mathrm{Ml}$ building sentences with cards. 


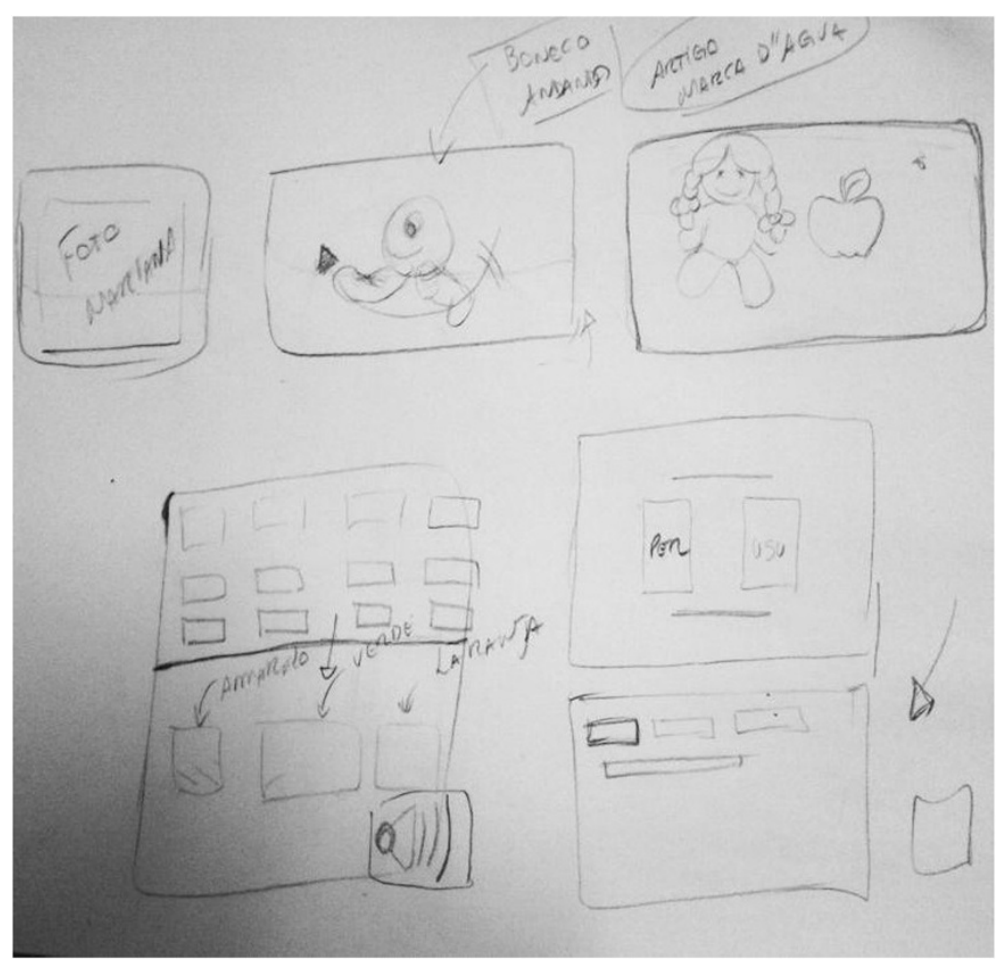

Figure 7 Paper prototype of the application interface.

subject, verb, and complement by using images. By observing how MI interacted with the cards, sliding them on the table, we inferred that MI prefers dragging and dropping the cards instead of 'clicking' on them.

Designing the interface In another session, the research team proposed a paper prototyping activity, in which a user interface for MI's apparatus should be defined (Figure 7).

Also in this stage, the specialist members of the devteam suggested some more requirements as follows. Such suggestions were based on MI's needs and on what was observed in previous PD practices with her.

The application should provide support for another user role (Figure 8) with customization functionalities such as adding, changing, and removing sounds and images either from files downloaded from the web or produced with the tablet applications.

The first icon in the image list under the subject category should be MI's own photograph, once, in her age, the notion of subject is still much connected with the notion of the self (Figure 9).

The icon that depicts the verb category was chosen based on the results from a test on whether MI recognized the conventional representation of movement in drawings, i.e., two parallel traces. However, she did not understand this convention. One of the research team members mimicked a statue and then pretended to be running. MI was asked, 'Is he still?', 'Is he moving?', and she correctly associated the mimicry to its meaning. Then, to depict the verb category, the stakeholders chose an animated icon, simulating a running man (Figure 9).

The icon that depicts the complement category must present some of MI's toys (Figure 9). These complements are related to the direct or indirect object category.

Figure 9 explains how the application works, when MI chooses a subject, a verb, and an object, in the correct order, and eventually presses the sound button for the sentence to be voiced.

Based on the paper prototypes and the suggestions previously presented by the specialist members of the devteam in the PD process, the computer science specialists produced a high-fidelity interface prototype (a prototype that is close to the final form and behavior of the goal software product [9]) as Figures 8 and 9 illustrate.

\section{Participatory evaluation of the product}

Evaluations and appreciations were carried out throughout the whole process among the group of specialists so as to reflect on the results regarding the product, especially concerning MI's inputs from the PD practices.

We highlight two critical participatory evaluation sessions during the system development: (1) the therapeutic decisions about the aspects of the solution that would 


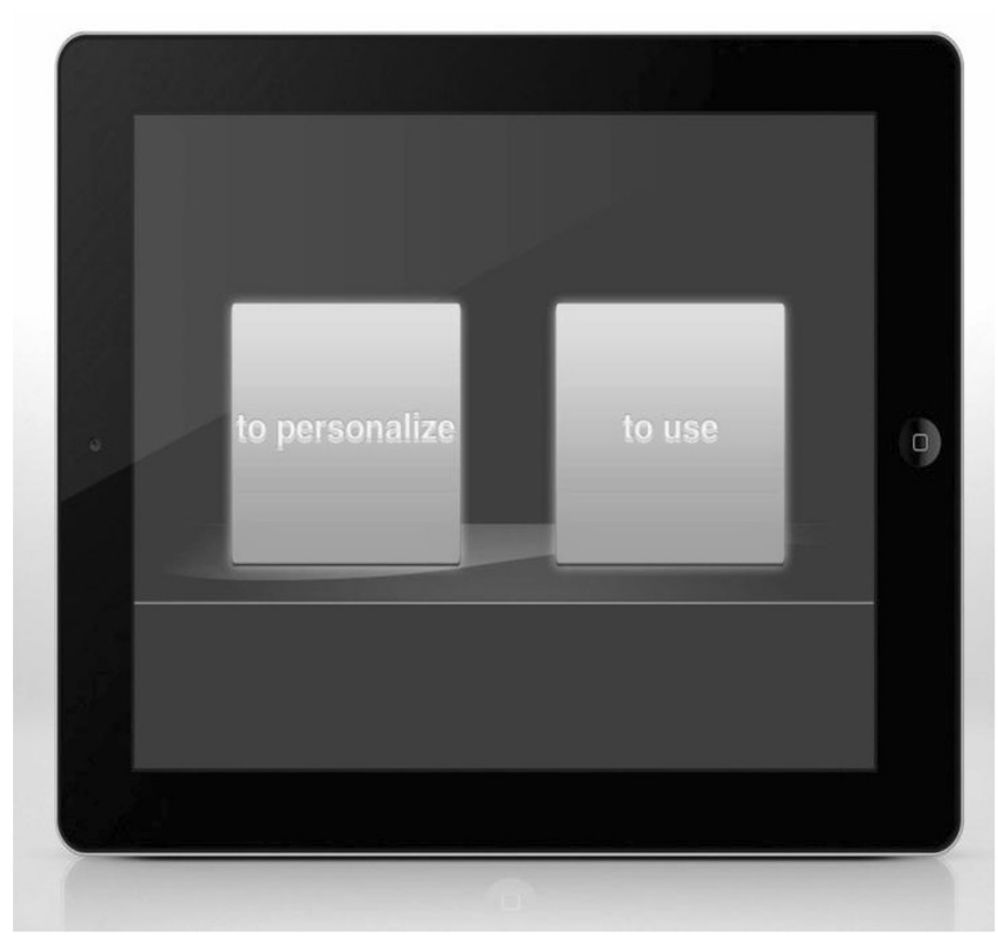

Figure 8 Interface level 1, permitting that MI's application is either personalized by a caregiver or used by the patient.

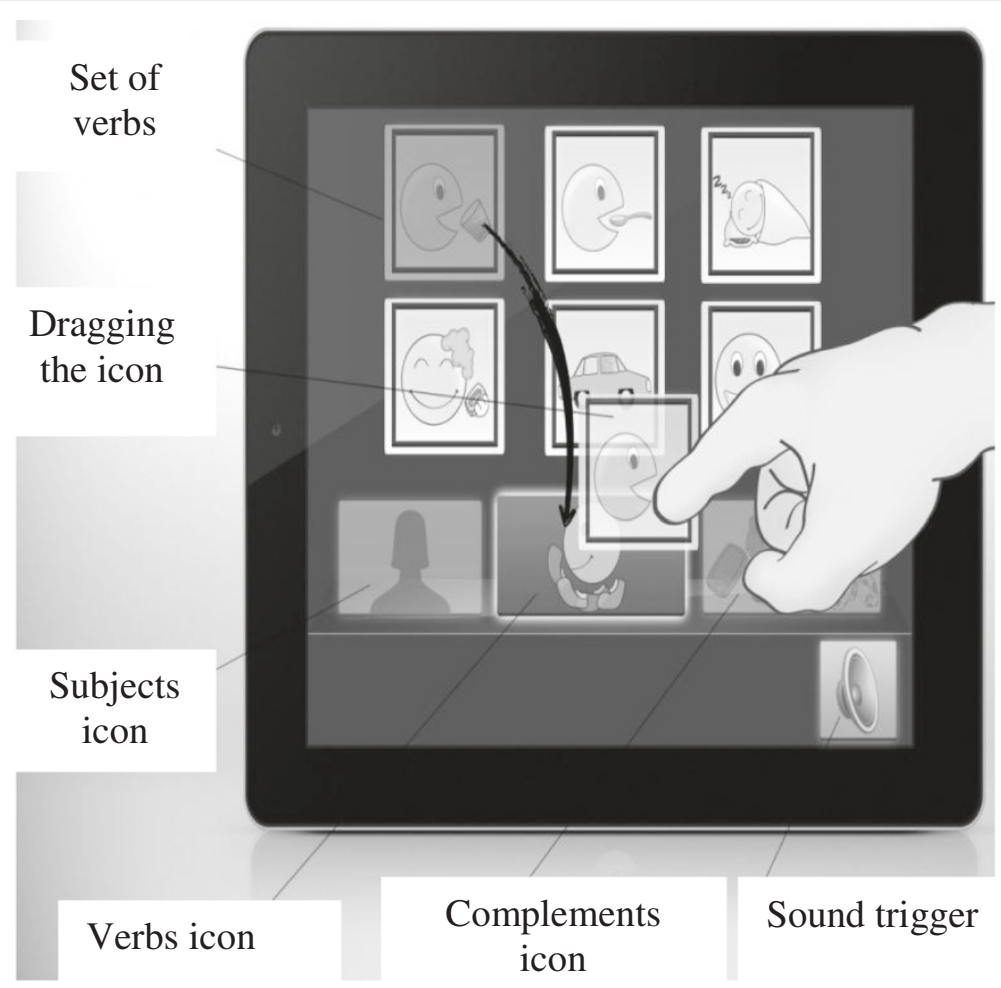

Figure 9 Interface level 2, Ml's application in use. 
effectively assist MI's rehabilitation and (2) the searching for a solution able to offer MI entertainment.

\section{Planning the participatory evaluation of the high-fidelity} prototype In order to prepare for the evaluation of the high-fidelity prototype with $\mathrm{MI}$, the research team ran a participatory evaluation of the product with the language and education scientists and MI's therapists.

The therapists and the language and education scientists were engaged in previously planned participatory design activities, so as to familiarize these participants with the process of evaluating a high-fidelity prototype. These activities focused on the use of the application, guided by a moderator who also observed the interaction with the solution. By the end of this activity, the therapists and the language and education scientists answered questions posed by the moderator, so that he could interpret their reactions to the usability and the accessibility of the solution.

As a result of these steps, the specialist members of the dev-team that acted as evaluators proposed a guide of activities to warrant MI's inclusion in the evaluation process. This guide was structured as follows.

The language scientist, chosen as the moderator in this practice, should introduce the child to the computational solution by inviting her to play a new game and presenting the tablet to her. The specialist stakeholder would make informal use of the high-fidelity prototype in the tablet and would role play some daily situations in which the child could use the application to communicate, as in case of thirst, hunger, or desire to play. We propose the following scenarios regarding these communicative situations.

The moderator should stand close to the child (so that he could watch her reactions), give her the tablet, and click on the icons for the subject 'MI', the verb 'wants', and the complement 'water'. The therapist would give him a glass of water. He would drink the water and lay the glass on the table.

Other sentences could be generated with the communicator: 'MI wants the doll' - and a doll would be given to the moderator; 'MI wants a snack' - and some fruit would be given to the moderator, who would eat it; 'MI colors the drawing' - and a black and white drawing would be given to the moderator, who would color it.

After presenting some of these communication possibilities to the child, the child should be invited to play with the tablet.

The child would first be allowed to test the icons at random, listening to their sounds, looking at their pictures and interacting with the application.

After this exploratory step, some objects should be gathered on the table but far from the child, so as to stimulate her to use the communicator to ask for them.
This test ought to be simple but permitting the child to explore the categories of subject, verb, and complement related to her daily routine and to her interaction with other people. Therefore, this test should comprise only a few words and icons: for the subject category, only MI's name (represented by the photo of MI); for the verb category, the options 'want', 'eat', 'drink', 'play', and 'color' (inflected according to the Portuguese rules), for example; for the complement category, 'snack', 'water', 'cell phone', 'doll', 'drawing', 'apple'. etc.

Hence, coherently produced sentences could be, for instance: 'MI wants water', 'MI drinks water', 'MI wants the snack,' 'MI eats the snack', 'MI colors the drawing', etc.

In case the child expresses herself by gestures, or any other non-verbal language to ask for the objects on the table, she must be indirectly stimulated by the moderator to use the application. For example, this can be done by telling the child that the other people in the room cannot understand her, so that she should try using the communicator.

The caregivers should help customizing the solution according to the expressions the child might need in her routine. The therapists and caregivers must help in the communication process with the child, while the therapists and the language scientist evaluate the use of verbal communication. After these stimuli, the child should be observed in free interaction with the application.

The participatory evaluation of the high-fidelity prototype with MI The subsequent session took about 90 min. The evaluation session was held at MI's school, in a separate room offered by the coordinator, so that external activities did not influence on the process.

MI's teacher brought her in the wheelchair and placed the girl at the same table she uses in her classroom activities, previously brought to this room. MI looked more at ease with the multidisciplinary team and the PD practice, thus smiling when she saw the group.

MI's psychologist and the language scientist sat beside the girl to act as moderators in this practice. Two computer scientists, who also act as participants of the dev-team, provided technical support in the use of the application and filmed and photographed the activity.

The educational psychologist sat at another table, close to MI, in order to help the psychologist throughout the practice, especially handing to her the necessary objects for each activity. On MI's table, the stakeholders placed the following objects: a tray with fruit (pieces of watermelon and apple), a glass of water, her favorite doll, a puzzle, blank paper, crayons, and the tablet with the prototype. Figure 10 shows this scenario.

The psychologist started the session by talking to MI about what had been done in the other PD sessions, also telling her that she would see the result of the previous 


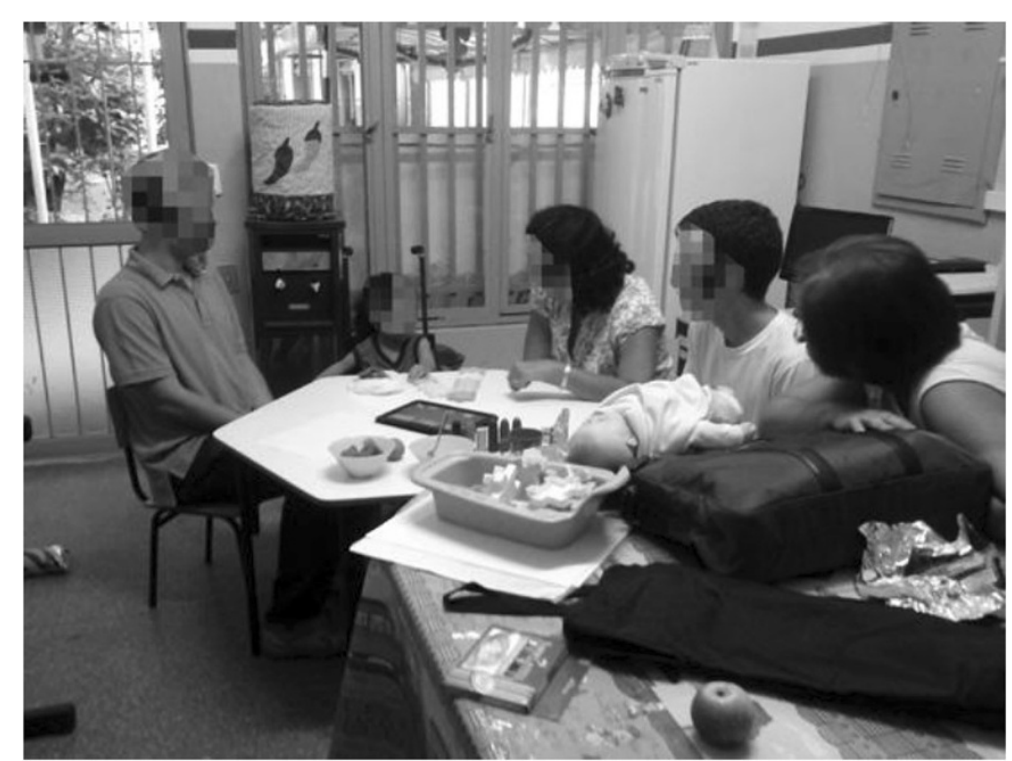

Figure 10 Scenario of the participatory evaluation of the high fidelity prototype.

practices in that moment. MI expressed that she remembered the previous sessions, and she was happy with the application.

Then, the language scientist used the communicator, showing MI how he interacted with the solution. This moderator said he was thirsty and clicked on the icons for 'MI drinks water'. After that, he gave a glass of water to MI, who took a sip. In addition to that, the moderator clicked on the icons for 'MI colors the drawing' and gave her a sheet of paper and crayons. MI colored the drawing. Figure 11 shows this step.
Next, the tablet was given to MI, who was encouraged to play with it. The psychologist suggested that MI clicked on the icons for 'MI drinks water'. MI selected the correct icons skillfully and structured the right sentence. After the tablet emitted the sound of the sentence, the glass of water was handed to MI again.

MI was also stimulated to express the sentence 'MI eats an apple'. Again, MI selected the correct icons, the sentence was correctly generated and she was given a piece of apple, which she ate. The psychologist then suggested that MI asked for a toy. MI selected the icons for

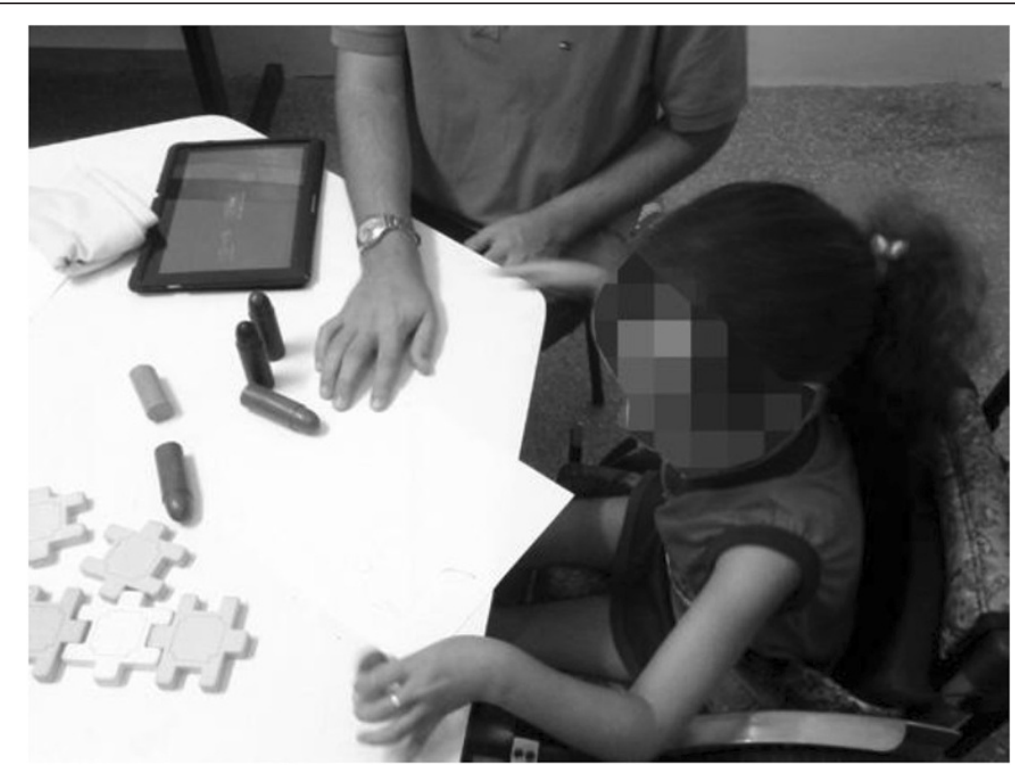

Figure $11 \mathrm{Ml}$ gets crayons and a sheet of paper after the moderator had expressed. 
'MI wants the doll'. The sentence was generated, and MI got the doll from the psychopedagogue. MI showed some emotion when she got the doll.

After that, MI was encouraged to express herself freely by using the communicator. She produced the sentence 'MI wants a snack'. The therapist asked if she wanted to have a snack, and she nodded her head affirmatively. The child was given some watermelon.

Some minutes later, MI was asked if she liked the communicator. She nodded her head affirmatively. MI was asked if she would like to use it again, and she nodded affirmatively again.

Back to the use of the application, MI produced the sentence 'MI drinks the drawing'. The language scientist questioned MI by telling her that MI does not drink a drawing; instead, MI drinks water. The psychologist asked if MI wanted to draw, and the child agreed.

The language scientist helped MI to click on the icon for each verb in the application, whereas the psychologist mimicked the actions related to those verbs, also using some of the objects on the table. For the verb 'color', she sketched on a sheet of paper; for the verb 'eat', she got a piece of watermelon and pretended to eat it; for the verb 'drink', she grabbed the glass of water and pretended to drink.

The psychopedagogue asked MI what she wanted to do, and the girl pointed to the crayons. The therapist checked if MI wanted to color. Then, the language scientist encouraged MI to produce the sentence 'MI wants the drawing' with the communicator. This time, MI chose the correct icons and was given a sheet of paper and crayons.

When the dev-team ended the session, MI was asked whether she would like to have a similar communicator for her daily routine at school or at home, to talk to others. She nodded affirmatively.

In a subsequent discussion about this practice, the specialist members of the dev-team agreed on these results:

- They were all satisfied with how MI used the communicator.

- They suggested that the tablet should comprise only the communicator and an application with a virtual keyboard, so that games and other applications would not divert MI's attention.

- A change in the interaction design was proposed because the icon of a loudspeaker, designed to be clicked to voice the sentence after it was structured, was not intuitively used by MI. The alternative design is to verbalize the sentence automatically after MI completes the choice on the subject, the verb, and the complement.
- Icons should be activated by a longer click, once dragging demands a bigger effort from MI.

\section{Guidelines for PD4CAT}

In a first action research cycle with PD4CAT, Borges et al. [3] presented generic guidelines for PD4CAT phases. Such guidelines can be briefly summarized as follows:

1. Observations help the approximation and perception of the patients' particularities.

2. Therapists' potential enriches the creation of resources and strategies that involve the patient in PD.

3. Caregivers' potential is necessary to help the communication with patients.

4. It is important to respect the patient's possibilities (time, flexibility).

5. The moderator must be careful when checking the understanding of the patient's non-verbal communication, also avoiding any misinterpretation by the caregiver on the patient's expression.

As we stated in the previous sections, PD4CAT is a method that evolves continuously with action research.

From this second action research cycle with PD4CAT, we draw more specific guidelines for PD4CAT, concerning impaired users that bear some resemblance to MI. However, those more specific guidelines do not replace the ones presented by Borges et al. [3]; instead, the more specific ones complement the more generic ones.

In the following section, we present how PD4CAT was adapted due to the experience of designing with MI.

Notice that the guidelines refer to the inclusion of subjects like MI in participatory design practices. MI can be characterized, as a subject, by her age (a child) and, consequently, her life goals; by SSPI and, consequently, communication techniques; and by her academic life and, consequently, the presence of professionals from different disciplines. Guidelines are grouped according to the PD4CAT phase they are more relevant to, as follows.

\section{Team composition phase}

As this phase is intended to acclimatize the selected team to the PD practices, the child must be told about the process he is being invited to engage in as a codesigner. The child must be informed about the technology he will help creating, the activities he will participate in, who he will work with in the PD practices, and where these practices will take place, so as to make a conscious choice whether to participate or not.

The other members of the dev-team must have already been informed about such issues and agreed to participate. A moderator must be chosen beforehand to 
introduce the child to the proposal. It must also be decided in advance who will help the moderator in this task. In this sense, it is important that the moderator and the people who will interact closer with the child are more intimate to him, such as his caregivers or therapists.

Those stakeholders must help make the child at ease in the meeting sessions by means of games, soothing words, or just their presence in the room, whenever the child becomes uneasy or shy. Such stakeholders must also introduce the child to the other participants, so as to bring them closer to him.

It is also suggested to approach the child gradually, when dev-team members that are unknown to the child need to talk to him. Therefore, in the first PD practices, the dev-team members unknown to the child must observe how therapists, caregivers, and the child interact. Then, as the child becomes familiar with the presence of the recently met participants, other practices must engage the newcomers in interacting directly with the target user. The proposal presented to the child must be based in a context that stimulates his engagement in the team.

During and after the introduction to the proposal, the child's acceptance must be observed. The work with the multidisciplinary team can only be carried out if the child agrees to engage in the conception of his assistive technology by means of PD4CAT.

\section{Solution inception phase, solution detailed specification and participatory evaluation of the product}

Because a child as young as MI is not mature enough to point out objectively what he wants from an assistive technology, we suggest that such investigation is initially done with his caregivers or the rehabilitation specialists by means of brainstorming or focus groups.

Next, the dev-team must propose adapted techniques, which will allow the child to ratify or not the solution inception. They must as well help define the proposals that best stimulate the child concerning the technology under conception.

In the following phase, solution detailed specification, the process is repeated, as in the solution inception phase, but it is intended now to specify the details of the incepted solution with the child.

In the solution design phase, the specialist members of the dev-team propose techniques that will allow the child to contribute in the conception of the user interface of the solution.

The same happens in the participatory evaluation phase, in which an evaluation guide is specified by the specialist members of the dev-team, so as to make the necessary adjustments to include the impaired child in this process. In that phase, the specialist members of the dev-team evaluate the developed technology before the child, so that they can propose strategies to include him in this process.

\section{Beyond PD4CAT phases}

Considering a target user similar to MI in terms of age, cognition, and skill levels, some strategies can be adapted to include the final user in the PD, beyond PD4CAT phases, as follows.

Relax the child in each practice It is important to make the child at ease in the beginning of each PD practice before engaging him in the activities. As aforesaid, a child can unwind by means of games, soothing words, or just the presence of close people in the room, kidding or talking to him.

Involve by pleasure Due to the early age and the consequent communication limits to express his needs, the child must be engaged in pleasant PD activities, such as games, drawing, and storytelling, so as to produce inputs for the PD.

Use proxies to explore potentials It is also suggested to explore the child's potential, giving him support to overcome his limitations in order to measure the target user's capacities.

Capture and apply the subject's communicative strategies As for the communication with the impaired user during the PD practices, the dev-team can use the same strategies the user uses in his daily life, such as paper communication boards, and specific gestures used in daily routines.

Double check assumptions Double checking with the dev-team all the information given by impaired user is important to avoid misinterpretation.

It is recommended to engage experts in the dev-team, in order to find alternatives to overcome the patient's limits and explore his abilities. In MI's case, it was important to have therapists, language and communication scientists, computer researchers, and a designer in the team.

Finally, it is noteworthy that, when assistive technology grows similar to a computer-aided therapy, it is necessary to empower the specialists on the specific area, so as to specify the patient's therapeutic needs. In MI's case, this empowerment was given to the therapists and the language scientist, but empowerment was given as well to the patient in order to warrant high usability to the interface. 


\section{Evaluation results}

From this case study, one can argue that MI did not participate actively in many practices of the solution inception as we would expect of a participatory design subject. This leads to question: 'was there real participatory design with MI or was she only included in user-centered design practices?'

On the other hand, specialist members of the dev-team were actively participative in both adjusting the techniques to include MI and in designing the solution.

We conclude that participation cannot be measured in an absolute scale because it is directly related to the capacities the team member brings to the process. While rehabilitation specialists were qualified to propose the requirements of a solution intended to help MI in her therapy, the language specialist was more qualified to define requirements that addressed pedagogical aspects of language acquisition. All of them participated jointly in the design sessions. From this point of view, MI's participation was as active as any other team member because she provided the peculiar knowledge she possessed about herself and her capacities and limitations, even though she was not able to have the intention of participation. Her non-intentional participation did not hinder the meeting of the usability expectations as far as we could evaluate by the time this paper was accepted for publication.

The final apparatus - MI's communicator - allows necessary gradual adjustments to the solution as time goes by in order to meet the further needs the patient will evidently have in her language acquisition process.

We understand that participatory evaluation sessions with prototypes even though they can be high-fidelity ones, as we have done so far, is not enough to warrant a fully positive acceptance of the developed solution. A longitudinal evaluation process must be carried out, so that we can observe and evaluate how the final user incorporates the solution in routine activities.

However, from the results from each phase of PD4CAT we have to so far, we can say that the dev-team have positively evaluated the following usability attributes: ease of use and pleasure. In terms of independence in routine activities and communication and rehabilitation and oral language acquisition, more research is to be done, especially in longitudinal evaluations, as changes in the human behavior take time.

From what we observed in the design process, some advantages of using the PD4CAT method include:

1. The possibility of creating a customized solution that meet the impaired user's needs and expectations based on the contributions from all the subjects involved, especially the impaired user, therapists, and caregivers (target users).

2. Good chances of acceptance of the product.
3. The target users express a sense of ownership over the solution and, for example, manifest pride for it in the rehabilitation institute.

4. Target users express their satisfaction for participating and contributing in the creation of the product.

5. Appropriation of HAT by therapists, who can improve their capabilities of prescribing such products for their patients.

We can see that the traditional UCD methods do not allow end users to manifest and participate in the solution design in such a great extent. This PD proposal permits that engagement, so that impaired users can act as co-designers of the customized solution jointly with therapists and caregivers.

Based on the literature review we made, only one research [21] presents a PD method with a similar end user. However, although that research provided some guidelines for PD4CAT (as it was mentioned in the 'Literature review' section of this paper), their method addressed only impaired users with aphasia and did not focus on the customization of the solution to the impaired user.

In turn, PD4CAT allows the engagement of disabled people in general and it also allows the customization of the solution. We understand that every new cycle improves the process, refines the method and the guidelines, in order to broaden the scope of PD4CAT.

\section{Conclusions}

In this paper, we have reported the results of an action research to design a communication device to help a non-verbal child develop his language skills.

PD4CAT method was improved to guide the involvement of different stakeholders as co-designers in the software development process. This improvement enabled the direct engagement of a SSPI child in the participatory design practices, which is shown by the case study of designing with the child MI. Based on this study, guidelines are presented in this research, which can be used by researchers in this field.

Future studies must be accomplished in two directions. Regarding the communicator, a longitudinal study must be addressed on the real use of the product, as well as a discussion on its customization to meet other users' specific needs. Moreover, it is necessary to deepen research on how this method can incorporate specific questions of language acquisition, such as more complex syntactic structures, pronunciation, and word formation.

Because PD4CAT is continuously improved in action research, we expect that each subject will bring new challenges to make PD4CAT more general and useful. Besides, considering customized solutions that meet an 
impaired user's needs new studies could adapt PD4CAT to meet the needs of a broader group of disabled people. One possible method would be adapting PD4CAT according to Melo and Baranauskas [14], so as to take into consideration the diversity of users and contexts in the development of solutions and interfaces.

\section{Disclosure}

This paper expands further discussions from the paper entitled 'Towards a participatory development technique of assistive technology for mobility and speech impaired patients' [13]. It was invited for publication in an extended format for being awarded as the best paper in the conference. This paper was improved by further elaborating on the complete life cycle of the case study in which the evaluation process was implemented, as presented in the text.

\section{Endnotes}

${ }^{a}$ Low-fidelity prototypes are used to 'demonstrate the general look and perhaps the feel of interface; they are not intended to show in detail how the application operates. These prototypes are created to communicate, educate, and inform, but not to train, test, or serve as a basis from which to code. Storyboard presentations and proof-of-concept prototypes fall into this category' ([37], p. 78). In our research, we used storyboards and paper prototypes as low-fidelity prototypes.

${ }^{\mathrm{b}}$ High-fidelity prototypes are prototypes fully interactive and have complete functionality. 'Users can enter data in entry fields, respond to messages, select icons to open windows, and, in general, interact with the user interface as though it were a real product. They are high fidelity because they represent the core functionality of the product's user interface' ([37], p. 78).

\section{Competing interests}

The authors declare that they have no competing interests.

\footnotetext{
Authors' contributions

LCLFB is the main author of this paper, which is the result of her doctoral thesis in the Electrical Enginnering Graduate Program at Escola Politecnica, Universidade de São Paulo. Besides her academic research which comprises the literature review, Prof. Borges was responsible for the majority of the actions described in the paper. She led the development team; she has planned and conducted meeting and interviews, and collected all data regarding the method application and solution.

LVLF is LCLFB's research advisor. Her interests being in $\mathrm{HCl}$ and in the development of assistive technologies, she was responsible for the ideation of a participatory design method for developing assistive technology. She has participated in the definition and detailing of PD4CAT activities, as well as in field data interpretation for the method improvement.

$\mathrm{CM}$ has participated as a co-advisor and as a software engineering and $\mathrm{HCl}$ specialist, contributing to structuring the solution development. Also, he participated in the results discussions. VCP is the language scientist referred to in the article. He has been responsible for defining several requirements for the designed solution and has participated in the co-design sessions. All authors have contributed in drafting, writing and revising the manuscript and agree to be accountable for all aspects of the work, thus taking public responsibility for the content.
}

\section{Authors' information}

LCLFB (lucianafariaborges@gmail.com), CM (crismac@gmail.com) and VCP (viniciuscarpe@gmail.com) address at UFMT is Avenida Fernando Correa da Costa, 2367, CEP 78060-900 Cuiabá, MT, Brazil.

LVLF (Ifilguei@usp.br) address at USP is Avenida Professor Luciano Gualberto, trav. 3, 158 CEP05508-900 São Paulo, SP, Brazil.

\section{Author details}

${ }^{1}$ Escola Politécnica, Universidade de São Paulo, SP, Brazil. ${ }^{2}$ UFMT, IC-LAVI, Cuiabá, MT, Brazil. ${ }^{3}$ UFMT, IL, Cuiabá, MT, Brazil.

Received: 19 March 2013 Accepted: 21 February 2014 Published: 24 April 2014

\section{References}

1. Borges LCLF, Filgueiras LVL, Maciel C (2010) FATA: método para desenvolvimento de soluções interativas e personalizadas para reabilitação de pacientes em ambiente de fábrica de software de alta tecnologia assistiva, Proceedings of the IX Symposium on Human Factors in Computing Systems. Brazilian Computer Society, Belo Horizonte, Minas Gerais, Brazil, pp 201-204

2. Borges LCLF, Filgueiras LVL, Maciel C (2011) Towards a participatory development technique of assistive technology for mobility and speech impaired patients, Proceedings of the 10th Brazilian Symposium on Human Factors in Computing Systems and the 5th Latin American Conference on Human-Computer Interaction. Brazilian Computer Society, Porto de Galinhas, Pernambuco, Brazil, pp 247-256

3. Borges L, Filgueiras LVL, Maciel C, Vinicius C (2013) A customized mobile application for a cerebral palsy user, Proceedings of the SIGDOC'13. ACM, Greenville, NC, USA, 978-1-4503-2131-0/13/09

4. Strömberg H, Valtteri P, Veikko I (2004) Interactive scenarios - building ubiquitous computing concepts in the spirit of participatory design. VTT Information Technology, Sinitaival 6, FIN 33101, Tampere, Finland

5. Muller MJ, Wildman DM, White EA (1992) Taxonomy of participatory design practices: a participatory poster, Posters and short talks of the 1992 SIGCHI conference on Human factors in computing systems. ACM, Monterey, California, pp 34-34

6. Scrivener SAR, Ball $\amalg$, Woodcock A (2000) Collaborative Design: Proceedings of CoDesigning 2000. Springer, p 542. ISBN 9781852333416

7. Holmlid S (2009) Participative, co-operative, emancipatory: from participatory design to service design. First Nordic Conference on Service Design and Service. Innovation, Oslo

8. Moffatt K, McGrenere J, Purves B, Klawe M (2004) The participatory design of a sound and image enhanced daily planner for people with aphasia, Proceedings of the SIGCHI conference on human factors in computing systems. ACM, Vienna, Austria, pp 407-414

9. Preece J, Rogers Y, Sharp H (2002) Interaction design: beyond human-computer interaction. John Wiley \& Sons, Wiley, New York, p 544. ISBN 0471492787

10. Muller M (1997) Participatory practices in the software lifecycle. In: Helander MG, Landauer TK, Prabhu PV (eds) Handbook of Human-Computer Interaction. Elsevier Science, Colorado, USA, pp 255-297

11. Rocha HV, Baranauskas D (2003) Design e avaliação de interfaces humano computador. NIED/UNICAMP, Campinas, SP, p 244

12. Mcgrenere J, Davies R, Findlater R, Graf P, Klawe M, Moffatt K, Purves B, Yang S (2002) Insights from the aphasia project: designing technology for and with people who have aphasia. SIGCAPH Comput Phys Handicap 73-74:112-118, ISSN 0163-5727

13. Borges LCLF, Filgueiras LVL, Maciel C, Vinicius C (2012) Customizing a communication device for a child with cerebral palsy using participatory design practices: contributions towards the PD4CAT method, Proceedings of the 11th Brazilian Symposium on Human Factors in Computing Systems. Brazilian Computer Society, Cuiaba, Brazil, pp 57-66

14. Melo AM, Baranauskas MCC (2006) Design para a inclusão: desafios e proposta, Proceedings of VII Brazilian symposium on Human factors in computing systems. ACM, Natal, RN, Brazil, pp 11-20

15. Prior S (2010) $\mathrm{HCl}$ methods for including adults with disabilities in the design of CHAMPION. Atlanta, GA, doi: 10.1145/1753846.1753878

16. Allen M, McGrenere J, Purves B (2008) The field evaluation of a mobile digital image communication application designed for people with aphasia. ACM Trans Access Comput 1(1):1-26. doi:10.1145/1361203.1361208 
17. Allen M, McGrenere J, Purves B (2007) The design and field evaluation of PhotoTalk: a digital image communication application for people, Proceedings of the 9th international ACM SIGACCESS conference on Computers and accessibility. ACM, Tempe, Arizona, USA, pp 187-194, doi: 10.1145/1296843.1296876

18. Garzotto F, Bordogna M (2010) Paper-based multimedia interaction as learning tool for disabled children, Proceedings of the 9th International Conference on Interaction Design and Children. ACM, Barcelona, Spain, pp 79-88, doi: 10.1145/1810543.1810553

19. Black R, Waller A, Tintarev N, Reiter E, Reddington J (2011) A mobile phone based personal narrative system, Proceedings of the 13th international ACM SIGACCESS conference on Computers and accessibility. ACM, Dundee, Scotland, UK, pp 171-178, doi: 10.1145/2049536.2049568

20. Druin A (1998) The design of children's technology: how we design and why? Morgan Kaufmann, San Franscisco, pp 55-56

21. Frauenberger C, Good J, Bright WK, Pain H (2012) Interpreting input from children: a designerly approach, Proceedings of the SIGCHI Conference on Human Factors in Computing Systems. ACM, Austin, Texas, USA, pp 2377-2386

22. Guha ML, Druin A, Fails JA (2008) Designing with and for children with special needs: an inclusionary model, Proceedings of the 7th international conference on Interaction design and children. ACM, Chicago, Illinois, pp 61-64

23. Duysburgh P, Slegers K, Jacobs A (2012) Interactive applications for children with hearing impairments: a process of inspiration, ideation, and conceptualization, Proceedings of the 11th International Conference on Interaction Design and Children. ACM, Bremen, Germany, pp 240-243

24. Millen L, Cobb S, Patel H (2011) A method for involving children with autism in design, Proceedings of the 10th International Conference on Interaction Design and Children. ACM, Ann Arbor, Michigan, pp 185-188

25. Galliers J, Wilson S, Roper A, Cocks N, Marshall J, Muscroft S, Pring T (2012) Words are not enough: empowering people with aphasia in the design process, Proceedings of the 12th Participatory Design Conference: Research Papers - Volume 1. ACM, Roskilde, Denmark, pp 51-60

26. Bratteteig T, Bodker K, Dittrich Y, Mogensen PH, Simonsen J (2012) Routledge International Handbook of Participatory Design. Routledge Taylor \& Francis Group, New York, USA, p 320. ISBN 9780415694407

27. Mayhew D (1999) The usability engineering lifecycle: a practioner's handbook for user interface design. Morgan Kaufmann, San Francisco. CA

28. Hix D, Hartson H (1993) Developing user interfaces: ensuring usability through product and process. John Wiley \& Sons, New York NY

29. Sommerville I (2011) Software engineering. Pearson, Boston, ISBN 0-13-705346-0 2011

30. Barbosa SDJ, Santana B (2010) Interação humano-computador. Serie SBC-Sociedade Brasileira de Computação. Elsevier, Rio de Janeiro. ISBN 978-85-352-3418-3

31. ISO/IEC 25010 (2011) Systems and software engineering - Systems and software Quality Requirements and Evaluation (SQuaRE). System and software quality models. The international organization for standardization and the international electrotechnical comission. Switzerland, p 34

32. Slobin DI (1996) From "thought and language" to "thinking for speaking. In: Gumperz JJ, Levinson SC (eds) Rethinking linguistic relativity. Cambridge University Press, Cambridge, pp 70-96

33. Oetting JB (1999) Children with SLI use argument structure cues to learn verbs. J Speech Lang Hear Res 42:1261-1274

34. Gleitman LR (2009) The learned component of language learning. In: Piattelli-Palmarini M, Salaburu P, Uriagereka J (eds) Of minds and language: encounters with Noam Chomsky. Oxford University Press, Oxford, pp 239-256
35. Bugermeister BB, Blum LH, Lorge I (2001) Escala de maturidade mental, Colúmbia: manual para aplicação e interpretação: Columbia Mental Maturity Scale Trad Faria, HCM, 3rd edn. Casa do Psicólogo, São Paulo

36. Wechsler SM (1996) O desenho da figura humana: avaliação do desenvolvimento infantil manual para crianças brasileiras. Editorial Psy, Campinas, SP, Brazil, p 163

37. Rudd J, Stern K, Isensee S (1996) Low vs. high-fidelity prototyping debate. Interact J 3:1:76-85

doi:10.1186/1678-4804-20-10

Cite this article as: de Faria Borges et al:: The life cycle of a customized communication device for a child with cerebral palsy: contributions toward the PD4CAT method. Journal of the Brazilian Computer Society 2014 20:10

\section{Submit your manuscript to a SpringerOpen ${ }^{\odot}$ journal and benefit from:}

- Convenient online submission

- Rigorous peer review

- Immediate publication on acceptance

- Open access: articles freely available online

- High visibility within the field

- Retaining the copyright to your article

Submit your next manuscript at $>$ springeropen.com 